\title{
Explanation of the express method of the determination of steel grade by spark
}

\author{
Igor Nikiforov ${ }^{1}$, Pavel Maltsev ${ }^{1}$, Vladimir Ivanov ${ }^{1}$, Inna Barsuk ${ }^{2}$ \\ ${ }^{I}$ Pskov state university, Faculty of Mechanical and machine building, \\ Departament of Technology of machinebuilding. \\ Address: Lenin square 2, Pskov, 180000, Russian Federation \\ ${ }^{2}$ Pskov state university, Faculty of Mechanical and machine \\ building, Departament of Theory of machinery and machines. \\ Address: Lenin square 2, Pskov, 180000, Russian Federation.
}

\begin{abstract}
On the basis of physico-chemical theory of burning metal particles, the explanation known method of determining the grade of steel for the spark when it is grinding is performed. The features of formation of globules are reviewed and given them a brief description. The conditions for the formation of a spark in the processing of steels and alloys of various grades are researched.
\end{abstract}

Keywords: grinding, chips, spark, combustion, diffusion oxidation, globule, thermal defect.

\section{INTRODUCTION}

In the recent past, is widely used express method of determining the grade of steel by spark when grinding the sample [1]. This method is currently losing relevance, since many machine building plants has modern equipment for the chemical and spectral analysis. However, it is sometimes used, since it does not require expensive equipment, and if used properly, gives satisfactory results. Specified express method most in demand in the repair industry, at small plants.

Some of the steel, irons, hard alloys and nonferrous metals shows in Table I, moreover therein the characteristic of the beam sparks when grinding is submitted [2]. As seen from the table, the hallmarks of sparks during grinding of various materials are color sparks (at the beginning - i.e. near the grinding wheel, and at the end of the flight); volume of the beam sparks; maximum length of the flight; amount of flashes in sparks beam and the nature of their demonstrations (in the form of a bifurcation, or in the form of the "stars" - when scatter of a small sparks in different directions is take place).

Analysis occurring physical and chemical processes that underlie the said express method can promotes to a more correct understanding of phenomena and processes existent in the grinding surfaces of workpieces. Since diffusion-oxidation processes occurring on the surface of the workpiece and during combustion of the chips are very similar and taking place at significant temperatures (up to $1500^{\circ} \mathrm{C}$ and above [3]). As a result, thermal defects appear on the surface of workpieces: burns (visible and invisible), microcracks and phase transformation.

Clearly, the method of determination of steel grade and other metals by spark based on the specifics of burning metal chips after her removal from the area of grinding. The combustion process is primarily affected by: the initial temperature of the chips, the nature of its heat exchange with the environment, the diffusion-oxidation processes, the strength characteristics of the outer oxide layer and the value of the activation energy [4].

The exothermic oxidation reaction (with discharge of heat) is occur after the remove of the hot chips from the grinding zone. Metal is oxidized and if the temperature of surface of chips exceeds the melting temperature of the oxide film, then there is burning. In this case, the molten metal chips takes a spherical shape, formed the so-called globule. Simultaneously, the carbon, which presence in the steel, interacting with the oxygen forms carbon dioxide $\left(\mathrm{CO}_{2}\right)$ and with an additional discharge of heat.

Moreover, presence of alloying elements in the steel, such as magnesium, aluminum, silicon, manganese, cobalt, nickel, etc., is affects the chips burning, due to the fact that they have a melting point lower than that of iron. It should be also pointed that the enthalpy of formation of oxides all of the alloying additives is negative, which leads to an additional increase of the chips temperature.

Purpose of this work - to explain express method of the determination of steel grade by spark. 
Achieving performed based on the micrographic analysis of the globules as a part of slurry. This method of analysis has allowed to interpret the impact of visual effects that occur during grinding of construction materials.

The studies will contribute to obtain new knowledge about the course of oxidative processes, including occurring in areas of contact of single abrasive grains with the treated surface. Analogy between combustion chips and oxidation local area on the treated surface in this case is justified, since in both cases the processes takes place at high temperatures.

TABLE I

IDENTIFICATION OF METALS IN GRINDING SPARK

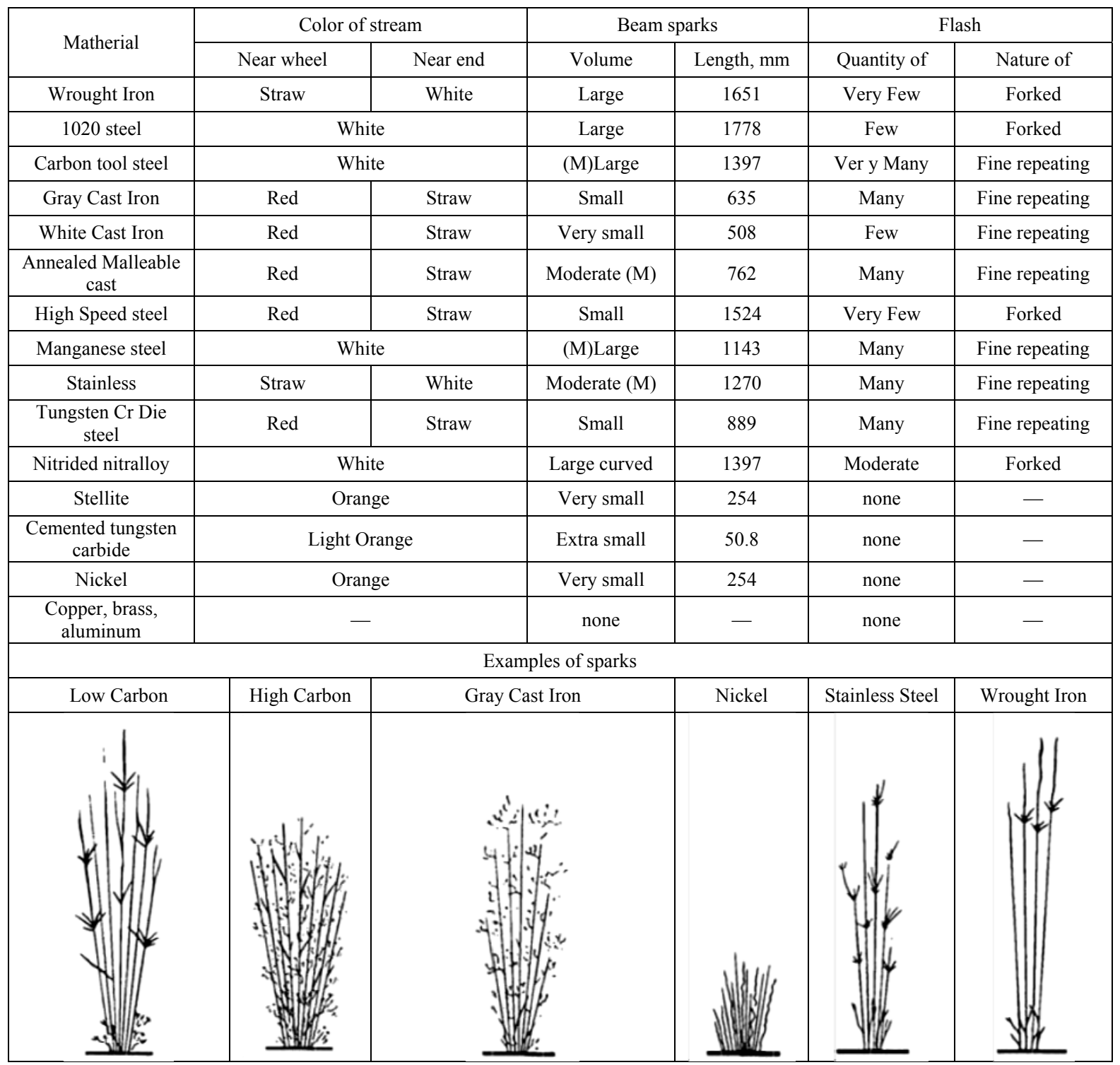

\section{MATERIALS AND METHODS}

On the surface grinding machine $3 \mathrm{G} 71$ handled specially made a samles of various structural materials wide range of applications and physical-chemical properties.

Cutting speed in all cases was equal to $35 \mathrm{~m} / \mathrm{s}$. As an abrasive tool for grinding steel, alloys and nonferrous metals was used grinding wheel of synthetic aluminum oxide white marks 24A, for grinding cemented-carbide composition - silicon carbide black marks 53C.

The slurry is collected through a sticky white tape, which installed in the removal zone of sparks, and studied by means of the microscope model Axiovert 40 MAT, designed for metallographic studies. Increase varied from $500^{\mathrm{X}}$ to $1000^{\mathrm{X}}$ (depending on the nature of the problem being solved and the best perception of the object of research). To solve the problem of small depth of field and produce 
three-dimensional image used computer software Helicon Focus.

A large number of globules in the slurry composition were analyzed, including at different stages of combustion of the metal particles. Followed by a statistical analysis of the results of research.
Micrographic images globules obtained as a result of conducted research. The most typical of which are presented in Table II. There are shown the corresponding beams sparks resulting from the treatment of some materials [1].

TABLE II

CONFORMITY OF BEAM SPARKS AND FORMED GLOBULES

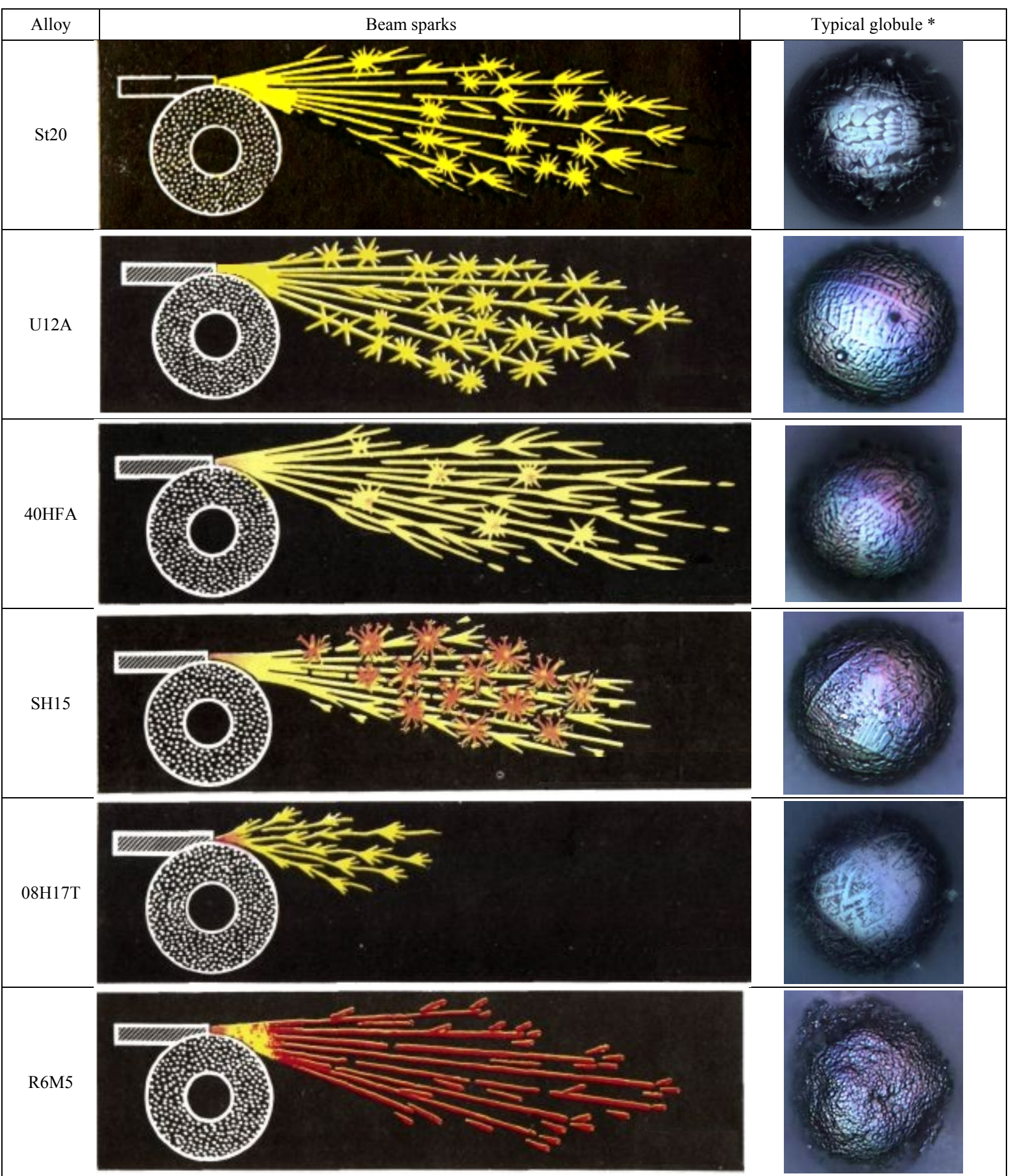



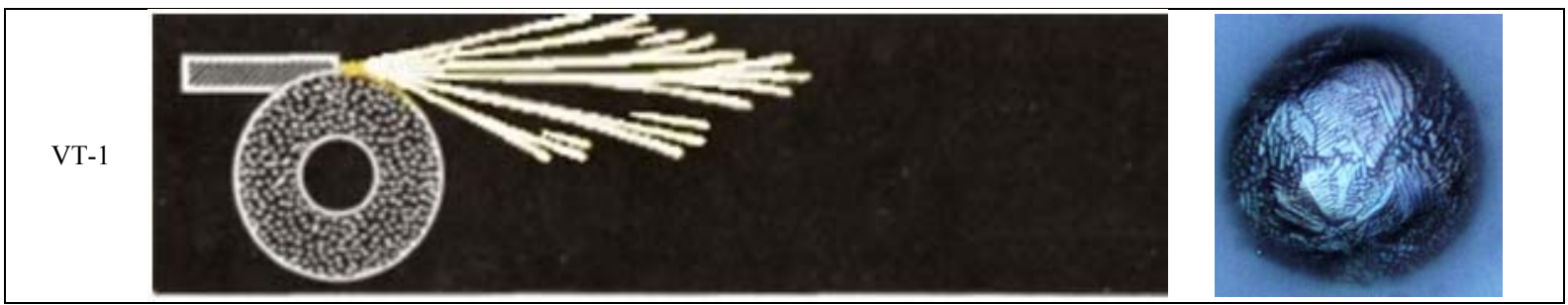

*Note: there are many other variants

\section{RESULTS AND DISCUSSION}

Microscopic analysis of spherical particles composed of grinding slurry and comparison the results obtained with the basic thesis of the theory of combustion and diffusion oxidation allowed to formulate the basic features of the formation of groups of globules, which are presented in Table III.

TABLE III

MICROGRAPHIC ANALYSIS OF THE GLOBULES IN THE COMPOSITION OF THE SLURRY

\begin{tabular}{|c|c|c|c|}
\hline Fig. & Material grade & $\begin{array}{l}\text { The features of the forming of globules and their } \\
\text { characteristics }\end{array}$ & Micrographs images of the final product \\
\hline 1 & Steel 20GS2 & $\begin{array}{c}\text { Alloying elements is reinforced outer oxide shell } \\
\text { and reduce its thermal conductivity. Superheated } \\
\text { metal breaks out, forming a plurality of ragged } \\
\text { holes and small globules. Result: globule with } \\
\text { small holes (oxide) and a plurality of small } \\
\text { globules (metal + oxide) }\end{array}$ & \\
\hline 2 & Steel 20 & $\begin{array}{c}\text { Superheated metal breaks out through the hole. } \\
\text { Result: globule with small dendritic structure } \\
\text { (metal + oxide) and large globule with a dendritic } \\
\text { structure (oxide). }\end{array}$ & \\
\hline 3 & $\begin{array}{c}\text { Steel } \\
\text { A11R3M3F2 }\end{array}$ & $\begin{array}{c}\text { Tungsten oxide forms a solid surface. Metal boils } \\
\text { and deforms the outer shell (metal + oxide). At } \\
\text { rupture of the shall forms a globule with a thick } \\
\text { wall (oxide). }\end{array}$ & \\
\hline 4 & $\begin{array}{l}\text { Cemented-carbide } \\
\text { composition } \\
\text { T5K10 и TN20 }\end{array}$ & $\begin{array}{l}\text { Slight burning. Globules solid and small size. } \\
\text { Present globule heterogeneous due to the presence } \\
\text { of the carbide phase. }\end{array}$ & \\
\hline
\end{tabular}

Volume of sparks beam is directly dependent on the quantity of burning metal and carbon dioxide. The more carbon in the alloy is, the higher the temperature of the chips, the more carbon dioxide, the more sparks. Alloying elements (manganese, silicon, chromium, etc.) produce on globules surface oxide film with a low thermal conductivity. This leads to a decrease the oxidation reaction (combustion) and reduce the volume of sparks beam. However, the oxygen continues to diffuse through the liquid oxide layer, which can lead to overheating of the metal inside. As a result, it is break out through the outer layer.

Alloying elements lead to hardening of the oxide layer in addition to reducing thermal conductivity of the outer shell [5]. The quantity of holes through which superheated metal break out depends on the strength of the outer layer (Table. III, Fig. 1). The appearance of the beam plurality of sparks scattering flares "stars" - is nothing more than the visualization of superheated metal, removed through the outer shell. Oxide shell does not have time to merge into a spherical shape, since the exothermic oxidation 
reaction terminated, cooling area is very large (due to the high level of dispersion), and the melting point of the oxide layer is great, and that it leads to rapid cooling and crystallization.

If there are no alloying elements and overheat the metal continues, then the metal break out, usually through a single hole. Metal and oxide shell scatter in different directions, according to the law of conservation of momentum - visually demonstrated in the bifurcation of the flares. Wherein metal instantly oxidized, that is occurs its autonomous combustion. The result of this process - the formation of two globules: oxide shell adopts a spherical shape with an explicit large-dendritic structure [6] and oxidized metal turns to a globule with small or mediumdendritic structure (Table. III, Fig. 2). Oxide shell have time to take spherical shape before crystallization, since it has a thick wall and contains a sufficient amount of heat, but sometimes there are shell with outer hole.

When grinding high-speed steel beam sparks is small and quantity of flares is insignificant. This is due to the very strong oxide shell, which is determined by the presence of tungsten. Metal inside the shell overheats and boils without break out to outside. The result is a globule with significant deviations from the spherical shape with a lumpy surface. In some cases, metal manages to break through the outer shell and then formed a thick-walled shell with a large hole (Table. III, Fig. 3) [7]. With an increase in the percentage of tungsten shells with holes is not observed. Molybdenum and nickel are also belong to alloying elements to significantly reinforcing oxide layer as well as tungsten.

When grinding tungstenfree cemented-carbide composition (such as TN20), we can see mainly combustion of nickel and molybdenum, wherein the sparks are few and globules are homogeneous or heterogeneous, due to titanium carbides. When grinding tungsten cemented-carbide composition (such as T5K10) mainly occurs combustion of cobalt wherein sparks are almost absent, and globules are homogeneous or heterogeneous, due to tungsten carbides (Table. III, Fig. 4).

Oxidation processes in grinding copper, lead, aluminum and some non-ferrous alloys are difficult [4] because of the low specific cutting force, directly affect the thermogenesis in the area microcutting (600 $\mathrm{N} / \mathrm{mm}^{2}$ - for duralumin, $550 \mathrm{~N} / \mathrm{mm}^{2}$ - for brass, 350 $\mathrm{N} / \mathrm{mm}^{2}$ - for lead, while for non-alloy steel, this indicator is $1500 \ldots 1700 \mathrm{~N} / \mathrm{mm}^{2}$, for high-temperature steel - $2400 \mathrm{~N} / \mathrm{mm}^{2}$ ) and because of high thermal conductivity of material of workpiece $(237 \mathrm{~W} / \mathrm{K} \cdot \mathrm{mol}$ for aluminum and $401 \mathrm{~W} / \mathrm{mol} \cdot \mathrm{K}$ - for copper). When grinding such metals sparks are not observed (Table. I).

Color change from red sparks - to a straw, from a straw - to white as they move (Table. I) can be explained by an increase of temperature of burning metal particles in the exothermic oxidation reaction.

\section{CONCLUSION}

1. Method of the determination of steel grade and other metals by spark is based on the features of oxidation (burning) of metal chips after it remove from the grinding area.

2. The emergence of single flashes in the beam sparks is a drop of superheated metal breaks out through the oxide shell.

3. The amount and nature of the demonstration of flashes depending on the characteristics of the outer shell and properties of metals, which are components of the alloy.

4. The main reasons affecting the presence of sparks in processing are specific cutting force and thermal conductivity of the material of the workpiece.

\section{$\mathrm{V}$ REFERENCES}

[1] I.Y. Sitanov, The determination of steel grade by spark. Moscow: Machine building, 1968, $16 \mathrm{pp}$.

[2] "Metal Identification by Spark Test with either a portable or stationary grinder" May 27, 2014. [Online]. Available: http://www. weldingwire.com/Images/Interior/documentlibrary/ metal\%20id.pdf. [Accessed: May 27, 2014]

[3] S. Chandrasekar, T.N. Farris, R.R. Hebbar, S.A. Hucker, and V.H. Bulsara, "Thermal Aspects of Surface Finishing Processes", ASM Metals Handbook: Surface Engineering, vol. 5, pp. 152-157, 1994

[4] L. Lu, T.N. Farris, and S. Chandrasekar, "Sliding Microindentation Wear Particles: Spheres in Grinding Swarf", Wear Particles: From the Cradle to the Grave, D. Dowson, C.M. Taylor, T.H.C. Childs, M. Godet, and G. Dalmaz, Ed., Elsevier, pp. 257-263, 1992

[5] D.V. Ardashev, "The photometric analysis of a shaving after grinding various steels", Metalloobrabotka, vol. 58, pp. 7-11, Aug. 2010

[6] S. Malkin, "Grinding of Metals: Theory and Application", Applied Metalworking, vol. 3, pp. 95-109, 1984.

[7] A.K. Tsokur, V.P. Tsokur, "Role of physical and chemical phenomena in thermal balance at grinding", Scientific papers of Donetsk National Technical University Series: Machinebuilding and Mechanical Engineering, vol. 124, pp5661, 2007. 